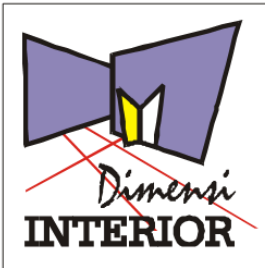

http://dimensiinterior.petra.ac.id

\title{
Kajian Implementasi Universal Design Pada Interior Perpustakaan Umum di Balai Pemuda Kota Surabaya
}

\author{
Airin Valentine | I GN. Ardana | Diana Thamrin \\ Program Studi Desain Interior, Universitas Kristen Petra, Surabaya \\ Email: airin.valentine@gmail.com
}

\begin{abstract}
ABSTRAK
Perpustakaan sebagai fasilitas publik dikunjungi oleh berbagai lapisan masyarakat termasuk anak-anak dan masyarakat yang memiliki kebutuhan khusus. Oleh karena itu, aksesibilitas dan penyediaan fasilitas perlu memperhatikan tujuh prinsip universal desain (TPUD). Universal Desain digunakan untuk merancang suatu produk/fasilitas agar semua orang dapat memanfaatkan tanpa harus melakukan proses adaptasi secara khusus. Tujuan dari penelitian ini adalah menganalisis penerapan TPUD serta mengusulkan solusi desain yang dapat diterapkan pada interior Perpustakaan Umum Balai Pemuda. Penelitian ini menggunakan metode kualitatif dengan pengumpulan data memakai metode observasi, wawancara, dan dokumentasi. Data yang diperoleh diolah secara deskriptif analitik. Hasil penelitian menunjukkan bahwa dari 13 ruang yang ada dalam Perpustakaan Balai Pemuda, hanya dua ruang saja yang memenuhi tujuh prinsip universal desain, sedangkan 11 ruang lainnya masih baru menerapkan beberapa prinsipnya saja sehingga membutuhkan solusi desain yang didasari oleh TPUD. Solusi desain yang diusulkan terdiri atas: (1) mengubah desain yang mudah digunakan bagi pengunjung dengan kursi roda, anak-anak, dan lansia; (2) mengubah tata letak fasilitas yang tersedia agar lebih efektif; (3) menambah keterangan pada signage untuk memperjelas informasi; (4) menambah sistem keamanan pada ramp dan stopkontak; (5) menambah desain toilet khusus difabel; serta (6) mendesain ulang area wastafel yang dapat digunakan oleh pengunjung dengan kursi roda dan anak-anak.
\end{abstract}

Kata Kunci: Interior, implementasi, perpustakaan umum, universal desain

\begin{abstract}
Library is one of the useful public facilities for all range of society including people with special needs. Therefore, accessibility and design of facilities should concider the Seven Principles of Universal Design (SUPD). Universal design is used to design a certain product or facility to be user-friendly. The purpose of this research is to analyze the application of SUPD, and to propose design solutions that can be applied to the interior of Balai Pemuda Public Library. This research uses the qualitative methodology and data were collected through observation, interviews, and documentation. The data were processed using descriptive analytic method. Findings show that only two out of 13 rooms applied SUPD, while 11 remaining rooms only applied several principles and hence needed design solutions based on SUPD. The proposed design solutions consisted of: (1) change of design to make it easier for wheel chair users, children, and eldery; (2) change of layout of the available facilities to be more effective; (3) addition of information on signage to clarify information; (4) addition of security system on ramps and electric sockets; (5) addition of disabled toilet, and (6) Re-design of the lavatory area that can be used by wheel chair users and children.
\end{abstract}

Keywords: Interior, implementation, public libraries, universal design.

\section{PENDAHULUAN}

Rendahnya budaya membaca pada masyarakat Indonesia menyebabkannya terlalu terbiasa menelan informasi secara instan, tanpa berupaya mencerna secara utuh sehingga cenderung dianggap benar. Fakta ini sudah dibuktikan oleh UNESCO (Organisasi Pendidikan Ilmu Pengetahuan dan Kebudayaan Perserikatan Bangsa-Bangsa) yang pada tahun 2012, menyatakan indeks membaca bangsa Indonesia hanya 0,001. Artinya, diantara 1000 orang, hanya satu orang yang membaca secara serius. Indonesia juga ditempatkan di peringkat ke-60 dari 61 negara, sesuai dengan catatan survey "Most Literated Nation in The World tahun 2015" [1]

Selain budaya membaca yang rendah, masyarakat Indonesia juga terbiasa membaca melalui internet yang belum tentu memiliki kebenaran 100\%. Terbukti sekitar 132,7 juta orang atau lebih dari separuh penduduk Indonesia (51,8 persen) telah menggunakan Internet, sesuai dengan hasil survey Asosiasi Penyelenggara Jasa Internet Indonesia (APJII) dan Polling Indonesia 2016. 
Kemunculan media baru digital ini menimbulkan gegar budaya di masyarakat, sehingga masyarakat begitu mudah menelan berita hoax karena hanya membaca sepintas tulisan online yang bahkan terkadang hanya membaca judul beritanya saja sudah berani membuat simpulan. Oleh karena itu, solusi jangka panjang yang dibutuhkan untuk menangkal isu ini adalah membangun literasi digital yang sebaiknya melibatkan sektor pendidikan seperti diajarkan ke sekolah sejak dini [1].

Berdasarkan fakta tersebut, maka perpustakaan merupakan jembatan menuju penguasaan ilmu pengetahuan yang berkontribusi penting bagi terbukanya akses informasi. Perpustakaan menyediakan data yang akurat bagi proses pengambilan sumber referensi, untuk pengembangan ilmu pengetahuan. Perpustakaan umum yang sering diibaratkan sebagai Universitas Rakyat atau Universitas Masyarakat, memang dimaksudkan sebagai tempat terbuka yang dapat difungsikan sebagai lembaga pendidikan yang demokratis karena menyediakan sumber belajar sesuai dengan kebutuhan masyarakatnya. Memberikan pelayanan tanpa membedakan suku bangsa, agama yang dianut, jenis kelamin, latar belakang dan tingkat sosial, umur dan pendidikan serta perbedaan lainnya. Banyak hal dapat terjadi jikalau tidak ada perpustakaan umum, seperti masyarakat akan kesulitan untuk mengakses literatur dan berbagai macam sumber pengetahuan yang tidak dapat diperoleh melalui internet [2].

Sebagai fasilitas yang secara faktual sudah dikategorikan bersifat publik, maka adanya keanekaragaman dan kebutuhan yang berbeda harus dipertimbangkan sebagai pedoman perancangannya agar semuanya diharapkan dapat dipenuhi satu persatu secara personal sekalipun. Oleh karena itu, setiap fasilitas jenis publik harus dapat mengakomodasi kepentingan semua kelompok masyarakat mulai dari yang kondisinya dikategorikan normal, anak kecil, penyandang cacat dan lansia. Salah satu srategi untuk dapat menyediakan fasilitas yang mampu memenuhi seluruh kebutuhan tersebut, yaitu dengan mempertimbangkan penerapan tujuh prinsip universal desain (TPUD).

Penelitian ini akan membahas mengenai kajian implementasi universal desain pada interior perpustakaan umum Balai Pemuda Kota Surabaya. Rumusan masalah pada penelitian ini adalah: (1) Bagaimanakah penerapan TPUD pada elemen interior di Perpustakaan Balai Pemuda? (2) Apa sajakah jenis solusi desain yang dapat diusulkan pada elemen interior perpustakaan umum Balai Pemuda Kota Surabaya agar memenuhi TPUD? Dari kedua rumusan masalah tersebut, maka tujuan dari penelitian ini adalah menganalisis penerapan TPUD, serta mengusulkan solusi desain yang dapat diterapkan pada interior Perpustakaan Umum Balai Pemuda agar memenuhi TPUD.

\section{METODE PENELITIAN}

\section{A.Metode Penelitian}

Metode yang digunakan dalam pelaksanaan penelitian pada Perpustakaan Umum Balai Pemuda ini adalah metode observasional melalui pengamatan data kualitatif dan kuantitatif yang akan diolah secara deskriptif analitik yaitu penelitian yang bermaksud untuk memahami fenomena tentang apa yang dialami oleh subjek penelitian misalnya perilaku, persepsi, motivasi, tindakan, dll., secara holistik, dan dengan cara deskripsi dalam bentuk kata-kata dan bahasa, pada suatu konteks khusus yang alamiah dan dengan memanfaatkan berbagai metode alamiah [3].

Pada penelitian ini metode analisis data yang digunakan adalah metode deskriptif kualitatif. Penelitian kualitatif bertujuan untuk penelitian yang pada akhirnya menghasilkan solusi desain. Design Thinking merupakan pendekatan metodologi yang dipilih dalam penelitian ini dengan mengadopsi pemikiran desain dari beberapa literatur yang disesuaikan dengan penelitian ini [4], [5], [6], [7].

Berdasarkan metode penelitian yang dipilih diatas, maka dapat disimpulkan tahap penelitian yang dilakukan adalah:

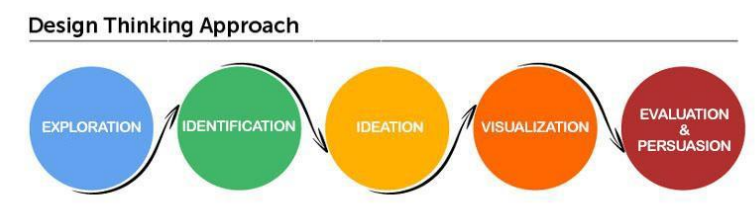

Gambar 1. Diagram Tahap Metode Penelitian Sumber: Olahan Penulis (2017)

\section{B.Kajian Teori}

Kajian teori yang dijadikan pedoman atau dasar dalam penelitian ini adalah TPUD yang dikemukakan oleh Ronald Mace [8], pendiri dan direktur program Pusat Universal Desain. Berikut adalah 7 prinsip umum untuk evaluasi desain universal dari The Center of Universal Design, di North Carolina, USA:

\section{Equitable Use}

Desain ini berguna dan berharga untuk orang dengan kemampuan yang beragam.

\section{Flexibility in Use}

Desain mengakomodasi berbagai preferensi individu dan kemampuan.

\section{Simple and Intuitive Use}

Penggunaan desain mudah dimengerti, terlepas dari pengalaman pengguna, pengetahuan, ketrampilan bahasa, atau tingkat konsentrasi pengguna.

\section{Perceptible Information}

Desain harus dapat menyediakan informasi yang diperlukan dan berkomunikasi secara efektif kepada pengguna, terlepas dari kemampuan seorang pengguna, kondisi lingkungan atau kemampuan indra pengguna.

\section{Tolerance for Error}

Desain meminimalkan bahaya dan konsekuensi yang merugikan dari tindakan disengaja maupun tidak disengaja.

\section{Low Physical Effort}

Desain dapat digunakan secara efisien dan nyaman dan dengan minimum menyebabkan kelelahan.

7. Size and Space for Approach and Use

Ukuran dan ruang yang disediakan sesuai dan cukup untuk pendekatan, capaian, manipulasi, dan 
penggunaan terlepas dari ukuran tubuh pengguna, postur, atau mobilitas tubuh pengguna.

Tujuh prinsip universal desain (TPUD) tersebut diatas menjadi dasar atau pedoman dalam penelitian ini. Selain TPUD, terdapat beberapa literatur yang mendukung penelitian ini, diantaranya adalah literatur mengenai ergonomi pengguna dan wayfinding / signage. Berikut adalah beberapa gambar yang mewakili.
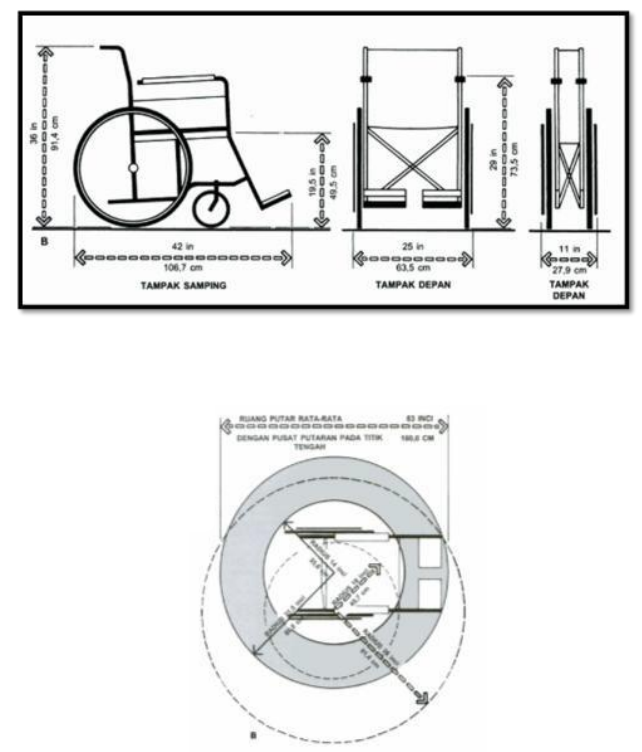

Gambar 2. Ergonomi Pengguna Kursi Roda [9]

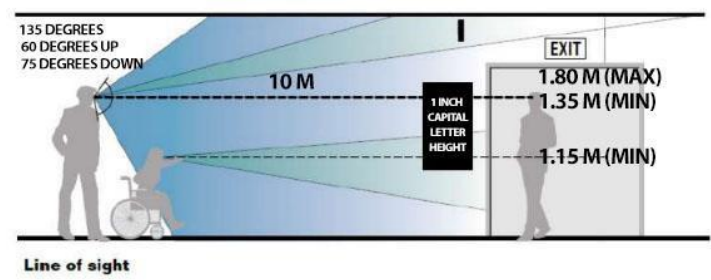

Gambar 3. Jarak Pandang Terhadap Signage Sumber: Olahan Penulis (2017)

\section{HASIL DAN PEMBAHASAN}

\section{A. Hasil Analisa}

Analisis dilakukan berdasarkan 7 prinsip Universal Design (TPUD) yang berurutan terdiri atas: (1) equitable use atau EU, (2) flexibility in use atau FU, (3) simple and intuitive use atau SIU, (4) perceptible information atau PI, (5) tolerance for error atau TE, (6) low physical effort atau LPE, dan (7) size and space for approach and use atau SSAU. Adapun unsur yang dianalisis pada interior Perpustakaan Umum Balai Pemuda Surabaya secara bertahap yaitu: (1) Akses Memasuki Bangunan; (2) Lobby; (3) Ruangan Loker; (4) Front Office; (5) Ruangan Majalah; (6) Ruang Kidsmart; (7) Ruangan Baca; (8) Ruangan anak \& Dyslexia Corner; (9) Bank Indonesia Corner; (10) Internet service area; (11) Korean Corner; (12) Ruangan Referensi \& Australia Corner; serta (13) toilet.
Hasil analisa ke-13 ruang yang ada di Perpustakaan Balai Pemuda Kota Surabaya berdasarkan TPUD menunjukkan bahwa hanya 2 ruangan saja yang menerapkan ketujuh prinsip universal design, yaitu (6) Ruang Kidsmart dan (10) Internet Service Area. Kesebelas ruang sisanya masih belum menerapkan TPUD, melainkan hanya beberapa prinsip universal design saja. Berikut adalah tabel rekapitulasi hasil analisa ke-13 ruangan berdasarkan TPUD:

Tabel 1. Kesimpulan Hasil Analisa

\begin{tabular}{|c|c|c|c|c|c|c|c|c|}
\hline \multirow[b]{2}{*}{ Area } & \multicolumn{7}{|c|}{ Universal Design Principles } & \multirow{2}{*}{$\begin{array}{l}\text { Perlu } \\
\text { Solusi }\end{array}$} \\
\hline & EU & $\mathrm{FU}$ & SIU & PI & TE & LPE & SSAU & \\
\hline (1) & $\checkmark$ & $\checkmark$ & $\checkmark$ & $x$ & $x$ & $\checkmark$ & $\checkmark$ & PI, TE \\
\hline (2) & $x$ & $\times$ & $\times$ & $\checkmark$ & $x$ & $\checkmark$ & $\checkmark$ & $\begin{array}{l}\text { EU, FU, } \\
\text { SIU, TE }\end{array}$ \\
\hline (3) & $\times$ & $x$ & $\checkmark$ & $\checkmark$ & $\checkmark$ & $\checkmark$ & $\times$ & $\begin{array}{l}\text { EU, FU, } \\
\text { SSAU }\end{array}$ \\
\hline (4) & $x$ & $\times$ & $\times$ & $\checkmark$ & $\times$ & $\checkmark$ & $\times$ & $\begin{array}{l}\text { EU, FU, } \\
\text { SIU, TE, } \\
\text { SSAU }\end{array}$ \\
\hline (5) & $\checkmark$ & $\checkmark$ & $\checkmark$ & $\checkmark$ & $\checkmark$ & $x$ & $\checkmark$ & LPE \\
\hline (6) & $\checkmark$ & $\checkmark$ & $\checkmark$ & $\checkmark$ & $\checkmark$ & $\checkmark$ & $\checkmark$ & - \\
\hline (7) & $x$ & $\checkmark$ & $\checkmark$ & $\checkmark$ & $\checkmark$ & $\checkmark$ & $\checkmark$ & EU \\
\hline (8) & $\times$ & $\times$ & $\checkmark$ & $\checkmark$ & $\times$ & $\checkmark$ & $\checkmark$ & $\begin{array}{l}\text { EU, FU, } \\
\mathrm{TE}\end{array}$ \\
\hline (9) & $\times$ & $\checkmark$ & $\checkmark$ & $x$ & $\times$ & $\checkmark$ & $\checkmark$ & $\begin{array}{l}\text { EU, PI, } \\
\text { TE }\end{array}$ \\
\hline (10) & $\checkmark$ & $\checkmark$ & $\checkmark$ & $\checkmark$ & $\checkmark$ & $\checkmark$ & $\checkmark$ & - \\
\hline (11) & $\times$ & $x$ & $\checkmark$ & $\checkmark$ & $\times$ & $\times$ & $\checkmark$ & $\begin{array}{l}\text { EU, FU, } \\
\text { TE, LPE }\end{array}$ \\
\hline (12) & $\times$ & $\times$ & $\checkmark$ & $x$ & $\checkmark$ & $\times$ & $\checkmark$ & $\begin{array}{l}\text { EU, FU, } \\
\text { PI, LPE }\end{array}$ \\
\hline$(13)$ & $\times$ & $x$ & $\checkmark$ & $\checkmark$ & $\checkmark$ & $\checkmark$ & $\checkmark$ & EU, FU \\
\hline
\end{tabular}

Dengan adanya tabel kesimpulan hasil analisa diatas, diketahui bahwa (1) Akses Memasuki Bangunan; (2) Lobby; (3) Ruangan Loker; (4) Front Office; (5) Ruangan Majalah; (6) Ruangan Baca; (7) Ruangan anak \& Dyslexia Corner; (8) Bank Indonesia Corner; (9) Korean Corner; (10) Ruangan Referensi \& Australia Corner; serta (11) toilet masih memerlukan solusi desain berdasarkan TPUD.

\section{B.Solusi Desain}

Setelah menganalisa ke-13 ruang berdasarkan TPUD, terdapat 11 ruang dalam Perpustakaan Umum Balai Pemuda yang belum memenuhi syarat, yaitu area akses masuk perpustakaan, lobby, ruang loker, front office, ruang majalah, ruang baca, ruang anak \& dyslexia corner, Bank Indonesia Corner, Korean Corner, Ruang referensi \& Australia corner, serta toilet. Untuk memperbaiki kekurangan ke-11 ruang tersebut, maka penulis memberikan solusi design berdasarkan TPUD. Selain mendesain berdasarkan TPUD, penulis juga mempertimbangkan corporate identity dari perpustakaan ini.Perpustakaan Umum Balai Pemuda memiliki corporate identity berupa warna oranye dan biru. Hal ini ditunjukkan melalui ruang front desk yang dominan menggunakan warna oranye dan biru baik pada perabot maupun panel dinding. Peran penulis disini adalah membantu Perpustakaan Umum Balai Pemuda untuk lebih menonjolkan corporate identity pada setiap ruang di 
dalam perpustakaan tanpa melupakan TPUD. Berikut adalah skema warna Perpustakaan Balai Pemuda yang digunakan penulis untuk memberikan solusi design.

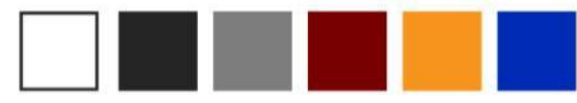

Gambar 4. Skema Warna Sesuai Corporate Identitiy Perpustakaan Umum Balai Pemuda. Sumber: Desain Penulis (2017)

1) Area Akses Masuk Perpustakaan

Pada area ini prinsip universal design ke-4 dan ke-5 tidak terpenuhi sehingga memerlukan solusi design. Solusi yang diterapkan pada prinsip ke-4 adalah menambahkan signage untuk memberi informasi mengenai letak perpustakaan. Hal ini dibutuhkan karena kurangnya signage pada area ini sehingga menyulitkan pengunjung dengan keterbatasan informasi.
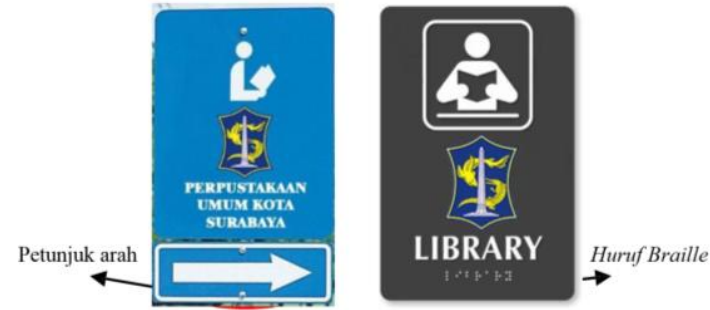

Gambar 5. Solusi desain area akses masuk Perpustakaan Umum Sumber: Desain Penulis (2017)

Hal yang bertentangan dengan prinsip universal design yang ke-5 adalah tidak terdapat railing untuk melengkapi ramp bagi pengunjung yang menggunakan kursi roda. Sudut kemiringan sudah cukup aman, yaitu $\pm 6^{\circ}$ dan memiliki tekstur kasar sehingga tidak mudah slip. Lebar ramp juga sudah cukup aman untuk dilewati pengunjung dengan kursi roda. Solusi desain yang dapat diwujudkan adalah dengan menambahkan railing pada kedua sisi ramp untuk mengurangi resiko terjadinya kecelakaan yang tidak diinginkan.
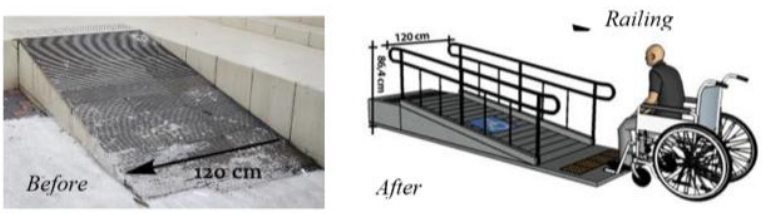

Gambar 6. Solusi desain untuk Railing pada Ramp Sumber: Desain Penulis (2017)

\section{2) Lobby}

Pada lobby, prinsip universal design yang tidak terpenuhi adalah prinsip ke-1, ke-2, ke-3, dan ke-5. Hal yang bertentangan dengan prinsip universal design yang pertama, ke-2, dan ke-5 adalah mengenai sistem swing pintu utama pada perpustakaan yang menyusahkan pengunjung dengan kursi roda dan anak-anak untuk mengoperasikannya. Selain itu juga pintu dengan sistem swing beresiko terjadinya kecelakaan yang tidak diinginkan seperti jari tangan pengunjung dapat terjepit. Solusi design yang dapat ditawarkan adalah mengganti pintu sistem swing dengan pintu geser

otomatis. Dengan menggunakan pintu geser otomatis, pintu tersebut akan terbuka dan tertutup secara otomatis dengan adanya sensor apabila terdapat pengunjung yang ingin masuk dan keluar perpustakaan.
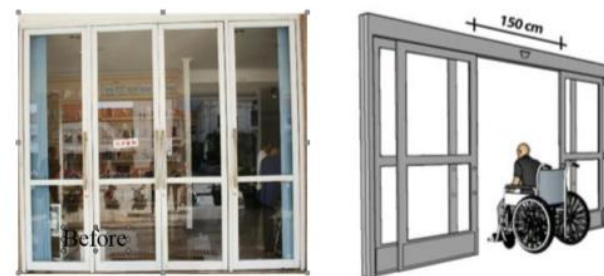

Sensor otomatis

Gambar 7. Solusi desain untuk pintu masuk Perpustakaan Sumber: Desain Penulis (2017)

Hal kedua yang tidak sesuai dengan prinsip universal design ke-1 dan ke-2 adalah mengenai meja penerima tamu pada lobby area. Ketinggian meja yang mencapai $120 \mathrm{~cm}$ membuat pengunjung dengan kursi roda dan anak-anak mengalami kesulitan untuk menggapainya. Solusi design yang dapat diterapkan adalah mendesain ulang meja tamu tersebut dengan ketinggian yang dapat dijangkau oleh pengunjung dengan kursi roda dan anakanak. Meja tamu ini didesain dengan ketinggian

$75 \mathrm{~cm}$ sehingga mudah dijangkau oleh pengunjung dengan kursi roda dan anak-anak. Selain itu pada bagian depan meja tamu didesain dengan space yang nyaman bagi pengguna kursi roda.

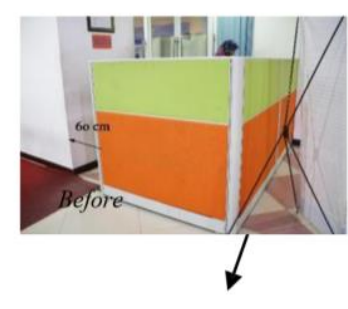

Tidak ada space untuk kaki pengunjung yang menggunakan kursi roda

Ketinggian meja terjangkau oleh pengguna kursi roda

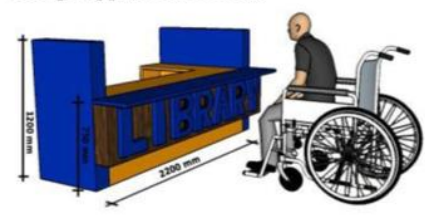

Gambar 8. Sol (2017)

Hal yang bertentangan dengan prinsip universal design yang ke-3 adalah mengenai peletakkan komputer katalog online yang terletak di balik pintu masuk sehingga tidak dapat terlihat langsung oleh pengunjung. Solusi design yang dapat diberikan adalah menukar letak meja katalog online dengan tanaman hias yang berada di samping sensor security alarm. Panjang meja katalog online adalah $90 \mathrm{~cm}$, sama dengan lebar area tanaman hias sehingga tidak ada masalah apabila ditukar tempat. Peletakkan meja katalog online di sebelah sensor security alarm dapat langsung terlihat ketika pengunjung memasuki 
perpustakaan karena letaknya berseberangan dengan pintu masuk utama.

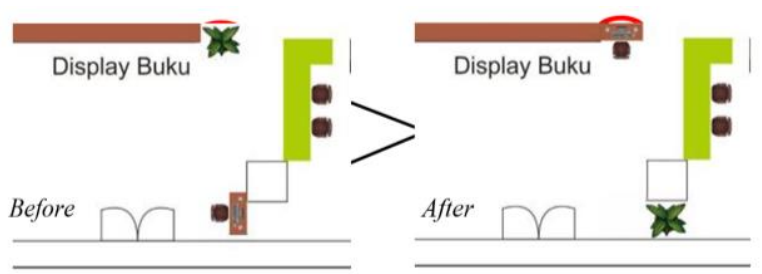

Gambar 9. Pertukaran posisi meja katalog online dengan tanaman hias Sumber: Desain Penulis (2017)

\section{3) Ruang Loker}

Pada ruang loker, terdapat 3 prinsip universal design yang tidak memenuhi syarat, yaitu prinsip universal design yang pertama, ke-2, dan ke-7. Hal yang bertentangan dengan prinsip universal design pertama dan ke-7 adalah jarak antara dinding dan meja tamu yang terlalu sempit untuk dilalui petugas pengguna kursi roda yaitu $60 \mathrm{~cm}$, sedangkan standar minimal adalah $80,3 \mathrm{~cm}$ [9]. Solusi yang dapat ditawarkan adalah mendesain meja tamu dengan lebar yang lebih pendek sehingga jarak antar meja tamu dan dinding menjadi $\geq 80,3 \mathrm{~cm}$.
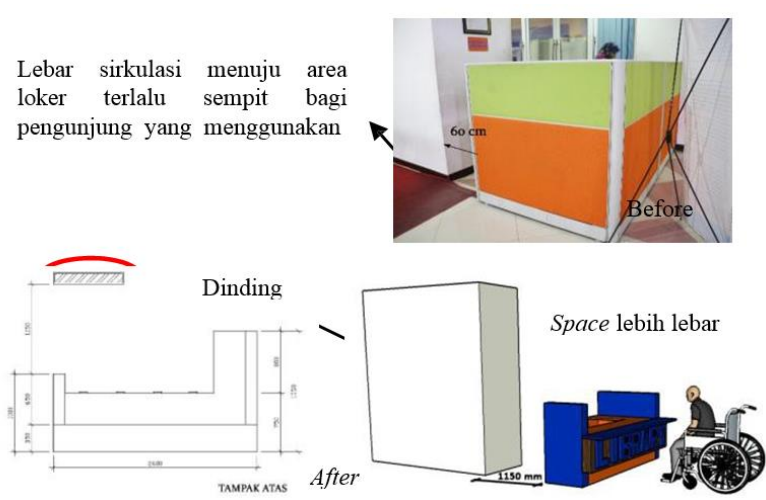

Gambar 10. Solusi desain untuk meja lobby. Sumber: Desain Penulis (2017)

Hal yang tidak sesuai dengan prinsip universal design yang ke-2 adalah pada bagian atas loker digunakan sebagai tempat meletakkan helm pengunjung karena ukuran loker terlalu kecil untuk helm. Hal ini membuat ruang loker terkesan kurang rapi dan bertentangan dengan prinsip universal design yang ke-2, yaitu flexibility in use. Solusi yang dapat ditawarkan adalah dengan mengubah ukuran masing-masing loker menjadi lebih besar agar helm dapat muat. Ukuran masing-masing loker yang ada di perpustakaan umum Balai Pemuda adalah 250 x 400 x $340 \mathrm{~mm}$. Sedangkan solusi desain yang dapat diterapkan adalah dengan mengubah ukuran loker menjadi 380 x 425 x 440 mm. Karena ukuran masing-masing loker lebih besar, maka secara otomatis jumlah loker juga semakin berkurang. Hal ini tidak terlalu menjadi masalah karena jumlah loker yang ada terlalu banyak sedangkan pada hari biasa tidak pernah penuh, sehingga dengan adanya desain baru ini kebutuhan pengguna masih terpenuhi.

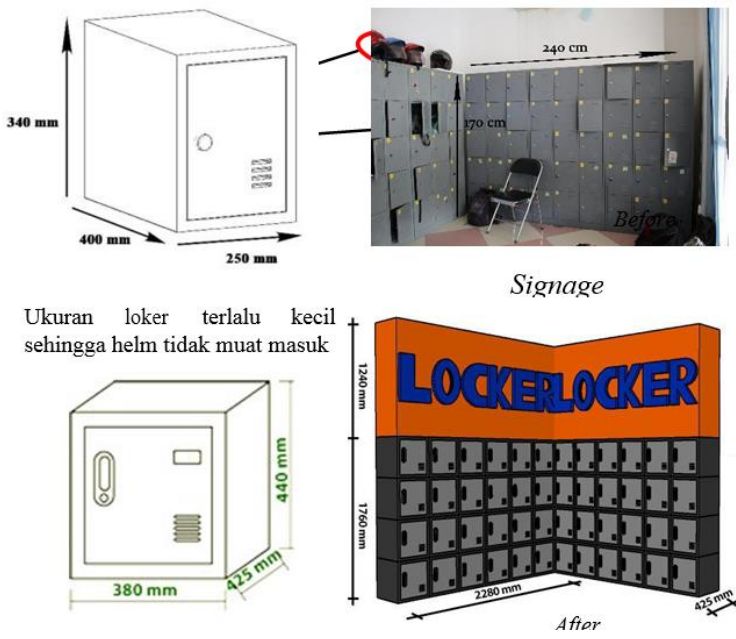

Gambar 11. Solusi desain untuk loker Perpustakaan Sumber: Desain Penulis (2017)

\section{4) Front Office}

Pada ruang front office, terdapat 5 prinsip universal design yang tidak memenuhi syarat, yaitu prinsip ke-1 (equitable use), ke-2 (flexibility in use), ke-3 (simple and intuitive use), ke-5 (tolerance for error), dan ke-7 (size and space for approach and use). Pada prinsip universal design yang ke-1, 2, 3, dan 5 berkaitan dengan desain front desk yang terdapat di ruang front office. Ketinggian front desk yang mencapai $120 \mathrm{~cm}$ menyulitkan pengunjung yang menggunakan kursi roda dan pengunjung anak-anak untuk berinteraksi dengan petugas. Hal ini bertentangan dengan prinsip universal design yang pertama. Solusi design yang dapat diterapkan adalah mendesain front desk dengan ketinggian yang berbeda / adanya leveling sehingga pengunjung yang menggunakan kursi roda dan pengunjung anak-anak dapat menggunakan front desk dengan ketinggian yang lebih rendah. Hal yang betentangan dengan prinsip universal design ke- 2 adalah pada bagian bawah front desk terlalu banyak barang sehingga tidak terdapat space untuk kaki petugas saat duduk. Solusi design yang dapat diterapkan adalah dengan memindahkan barang-barang yang terdapat di bawah front desk ke storage file. Selain memudahkan petugas dalam mencari file / barang, area ini pun menjadi terlihat lebih rapi.

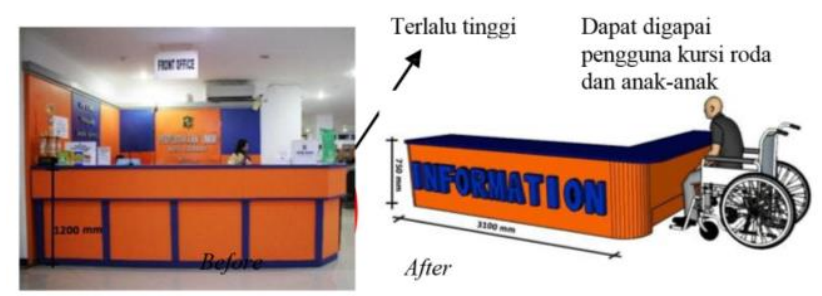

Gambar 12. Solusi desain untuk front desk. Sumber: Desain Penulis (2017)

Pada ruang ini belum terdapat storage file yang memadai sehingga harus menambahkan design untuk storage file. Hal yang bertentangan dengan prinsip universal design ke-3 dan ke-5 adalah pada bagian dalam front desk, barang-barang yang ada seperti buku-buku dan dokumen-dokumen diletakkan begitu saja sehingga menimbulkan kesan yang berantakan dan tidak 
terorganisir. Akibatnya adalah petugas dapat kesulitan untuk mencari file-file yang diperlukan serta terjadinya kemungkinan file yang terselip / hilang. Solusi design yang ditawarkan adalah dengan membuat sekat-sekat dengan signage yang berisi keterangan untuk masingmasing space agar lebih terorganisir. Berikut adalah solusi design front desk yang dapat diterapkan pada ruang front office.
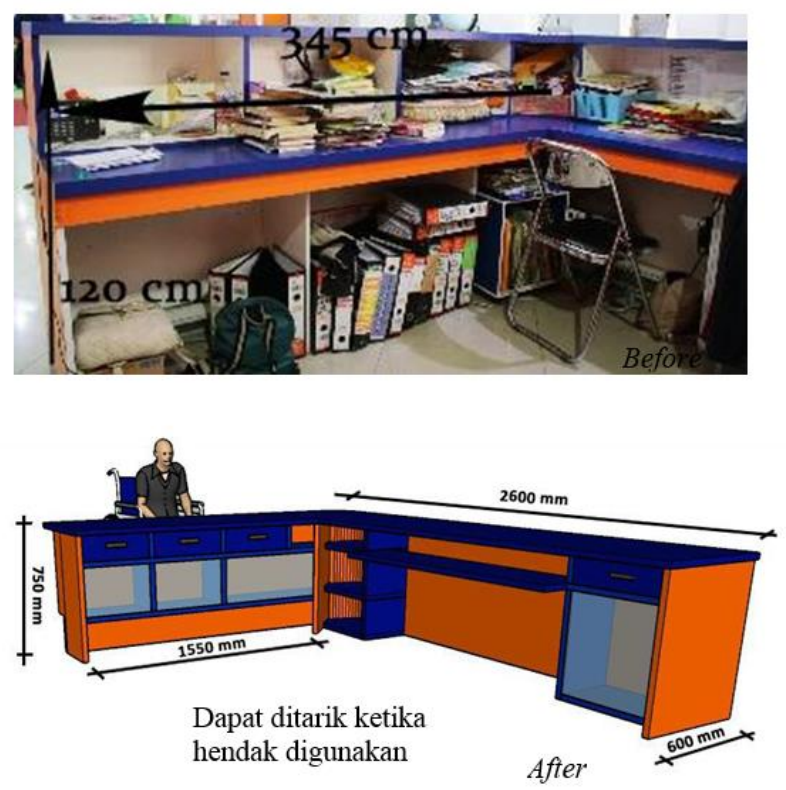

Gambar 13. Solusi desain untuk bagian dalam front desk Sumber: Desain Penulis (2017)

Hal yang tidak sesuai dengan prinsip universal design yang ke-7 adalah mengenai space yang cukup sempit di dalam area front office yang tidak memungkinkan pengunjung dengan kursi roda untuk bersirkulasi. Hal ini dikarenakan adanya kursi pada kedua sisi meja yang cukup memakan tempat. Solusi design yang dapat ditawarkan adalah dengan mengubah posisi kursi hanya pada salah satu sisi dan merapatkan meja printer pada dinding belakang sehingga tidak memakan banyak tempat. Setelah posisi diubah, maka area sirkulasi yang sebelumnya $128 \mathrm{~cm}$ berubah menjadi $184 \mathrm{~cm}$. Standar agar pengguna kursi roda dapat melakukan sirkulasi adalah $150 \mathrm{~cm}$ [9] sehingga dengan jarak $184 \mathrm{~cm}$ pengunjung yang menggunakan kursi roda dapat leluasa melakukan sirkulasi.
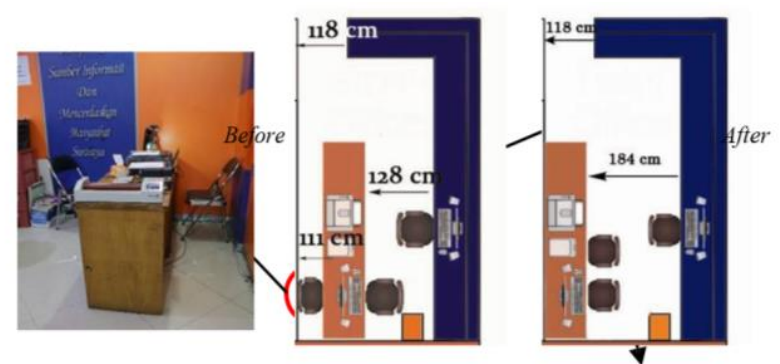

Area sirkulasi lebih

Gambar 14. Before \& after front desk area. Sumber: Desain Penulis (2017)

5) Ruang Majalah

Pada ruang majalah, hanya terdapat satu prinsip universal design yang tidak memenuhi syarat, yaitu prinsip universal design yang ke-6 (low physical effort). Terdapat kendala pada ketinggian rak majalah $(200 \mathrm{~cm})$ untuk pengguna kursi roda apabila ingin mengambil majalah yang berada di rak atas, sehingga hal ini bertentangan dengan prinsip universal design yang ke-6 yaitu low physical effort. Solusi design yang dapat ditawarkan adalah dengan mengubah design rak majalah menjadi lebih pendek $(120 \mathrm{~cm})$ sehingga dapat dijangkau oleh pengunjung dengan kursi roda. Walaupun lebih pendek, akan tetapi rak majalah ini tetap memiliki jumlah rak yang sama karena desainnya yang memiliki layer-layer sehingga tidak menjadi masalah dengan jumlah majalah yang banyak.
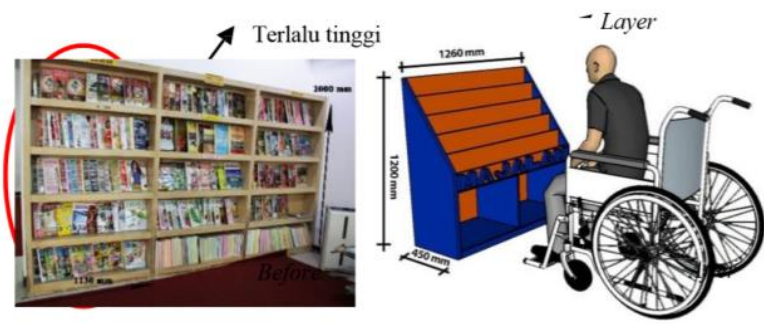

Gambar 15. Solusi desain untuk rak majalah Sumber: Desain Penulis (2017)

6) Ruang Baca

Pada ruang baca, hanya terdapat satu prinsip yang tidak sesuai dengan syarat universal design, yaitu prinsip pertama (equitable use). Ruang baca yang terletak di samping Korean corner memiliki meja pendek untuk duduk lesehan. Pengguna yang sudah berumur maupun yang memiliki kelainan pada sendi tentu akan kesulitan dalam menggunakan fasilitas ini. Oleh karena itu fasilitas ini masih belum memenuhi prinsip universal design ke-1, yaitu equitable use. Solusi design yang dapat ditawarkan adalah dengan mendesain meja yang lebih tinggi dan memiliki rongga pada bagian kaki meja sehingga pengunjung yang sudah berumur tidak duduk lesehan. Berikut adalah desain meja dan kursi yang dapat diterapkan pada ruang baca perpustakaan umum Balai Pemuda Surabaya.
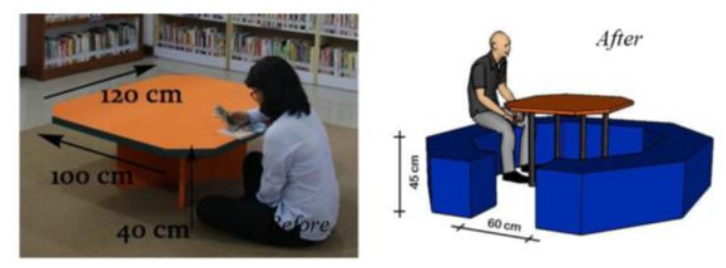

Gambar 16. Solusi desain untuk meja baca. Sumber: Desain Penulis (2017)

\section{7) Ruang Anak \& Dyslexia Corner}

Pada ruang anak \& dyslexia corner terdapat 3 prinsip yang tidak sesuai dengan syarat universal design, yaitu prinsip universal design pertama (equitable use), ke-2 (flexibility in use), dan ke-5 (tolerance for error). Hal yang tidak sesuai dengan prinsip universal design pertama adalah mengenai penggunaan puzzle floor mats pada lantai ruang ini. Pengunjung yang menggunakan kursi roda dapat mengalami kesulitan ketika memasuki ruang ini karena tekstur dari floor mats sendiri yang 
terlalu empuk. Solusi design yang dapat ditawarkan adalah mengganti floor mats dengan karpet. Walaupun karpet tidak senyaman floor mats, namun pengguna kursi roda dapat dengan mudah melaluinya, selain itu material karpet juga cukup aman dan nyaman bagi pengunjung anak- anak. Pemilihan warna karpet adalah warna abuabu dan oranye dengan pertimbangan warna abu-abu agar karpet tidak terlihat cepat kotor, sedangkan warna oranye merupakan corporate identity dari Perpustakaan Balai Pemuda.
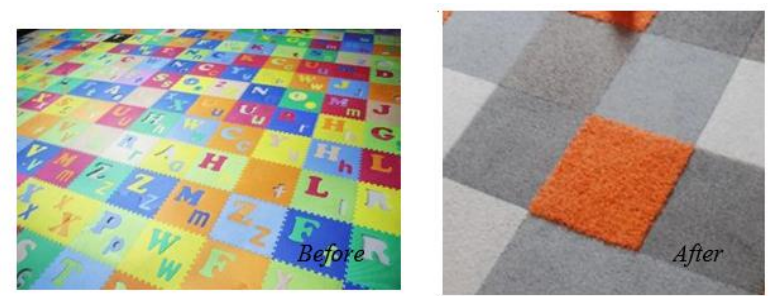

Gambar 17. Solusi desain untuk lantai Ruang anak \& Dyslexia corner. Sumber: https://id.pinterest.com/pin/170362798380849874/

Hal yang tidak sesuai dengan prinsip universal design yang ke-2 adalah tidak terdapat kursi pada komputer dyslexia di area ini sehingga apabila ingin menggunakan komputer ini pengunjung harus berdiri atau berlutut. Solusi design yang dapat ditawarkan adalah dengan mendesain kursi untuk diletakkan di depan masing-masing komputer sehingga pengunjung yang ingin menggunakan komputer dyslexia ini dapat duduk dengan nyaman. Design kursi yang ditawarkan adalah kursi yang mudah dipindah-pindah, oleh karena itu jenis kursi yang digunakan adalah office chair dengan roda dan backrest yang berfungsi untuk kenyamanan pengguna. Dengan adanya roda pada kursi memudahkan pengunjung memindahkan kursi tersebut terutama apabila pengunjung disable ingin menggunakan komputer tersebut.
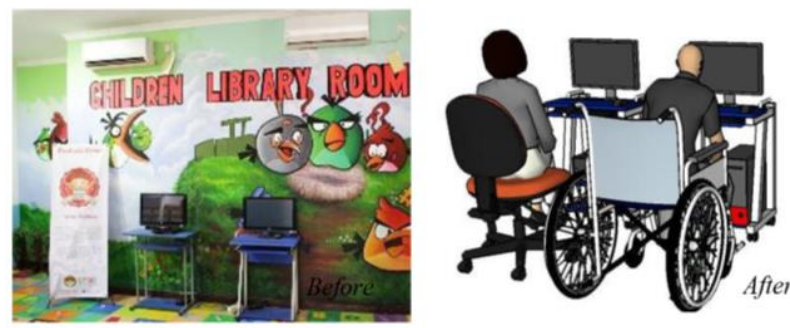

Gambar 18. Desain kursi komputer ruang anak \& dyslexia corner Sumber: Desain Penulis (2017)

Hal yang tidak sesuai dengan prinsip universal design ke-5 adalah peletakkan stopkontak pada dinding yang terlalu rendah. Ruang anak \& dyslexia corner ini ditujukan terutama bagi pengunjung anak-anak, sehingga akan sangat berbahaya (resiko tersetrum) apabila peletakkan stop kontak berada pada jangkauan anak-anak. Solusi design yang dapat ditawarkan adalah dengan memasang alat khusus untuk menutup akses stop kontak dan steker yang sedang terpasang. Dengan alat ini, pengunjung anak-anak tidak bisa sembarangan mencabut steker dari stop kontak.
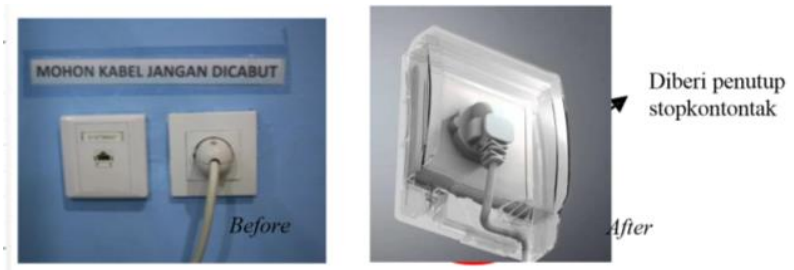

Gambar 19. Solusi desain untuk stopkontak. Sumber: https://www.safetysign.co.id/news/170/Tips-Agar-Anak-Aman-dariBahaya-Listrik-di-Rumah

\section{8) Bank Indonesia Corner}

Pada Bank Indonesia Corner terdapat 3 prinsip yang tidak sesuai dengan syarat universal design, yaitu prinsip universal design pertama, ke-4, dan ke-5. Hal yang tidak sesuai dengan prinsip universal design pertama yaitu mengenai ketinggian rak buku yang mencapai $195 \mathrm{~cm}$ sehingga menyulitkan pengguna kursi roda untuk menggapai buku pada rak paling atas. Solusi yang dapat ditawarkan adalah dengan memindahkan buku yang diletakkan pada rak atas ke rak bawah sehingga mudah dijangkau oleh pengguna kursi roda. Hal ini dapat dilakukan karena masih banyak space kosong pada bagian rak bawah, sehingga tidak masalah apabila buku- buku yang berada di rak atas dipindahkan ke rak bawah.

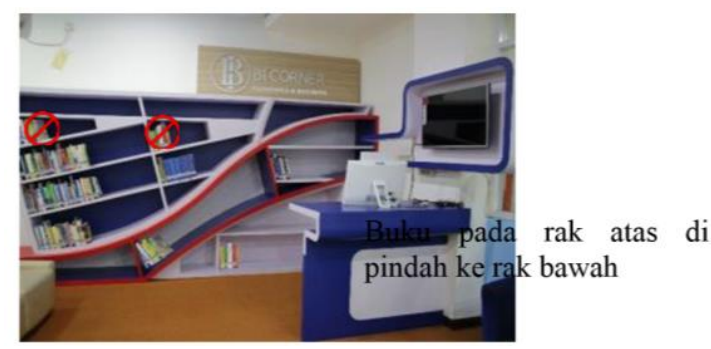

Gambar 20. Solusi desain untuk rak BI Corner. Sumber: Olahan Penulis (2017)

Hal yang tidak sesuai dengan prinsip universal design yang ke-4 adalah pada area Bank Indonesia Corner ini terdapat signage yang cukup besar bertuliskan "BI Corner". Signage ini memberikan informasi bahwa area ini adalah Bank Indonesia Corner. Karena ukurannya yang cukup besar dan jelas, maka signage ini mudah terlihat oleh pengunjung. Akan tetapi tulisan BI Corner ini mengandung informasi yang kurang jelas, padahal maksudnya adalah buku-buku yang ada di area ini merupakan buku-buku ekonomi dan bisnis. Solusi design yang dapat ditawarkan adalah menambah keterangan "ekonomi \& bisnis" dan "economics \& business" pada signage agar pengunjung mengerti bahwa pada area BI corner ini tersedia buku-buku mengenai ekonomi dan bisnis. 

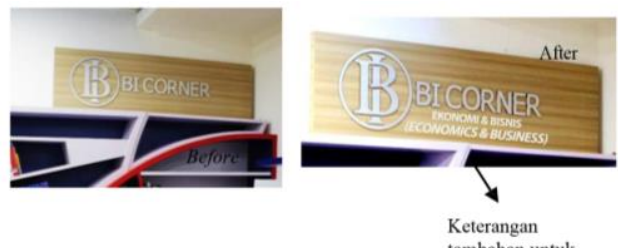

Keterangan tambahan untuk memperjela informasi

Gambar 21. Solusi desain signage BI Corner. Sumber: Desain Penulis (2017)

Hal yang tidak sesuai dengan prinsip universal design ke-5 adalah pada area ini terdapat televisi, namun tidak ada remote untuk menghidupkannya, sehingga memungkinkan anak-anak yang usil akan mengutak atik tv tersebut. Selain itu terdapat stopkontak di bawah televisi. Hal ini tidak menutup kemungkinan untuk resiko tersetrum. Solusi design yang dapat ditawarkan adalah dengan menyediakan remote tv diatas meja sehingga pengunjung dapat dengan mudah mengoperasikan televisi secara mandiri.
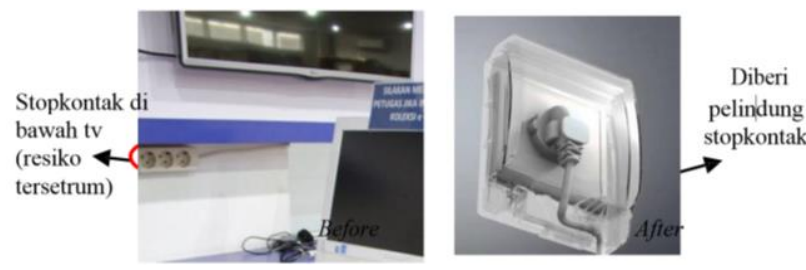

Gambar 22. Solusi desain untuk stopkontak pada BI Corner. Sumber: https://www.safetysign.co.id/news/170/Tips-Agar-Anak-Aman-dariBahaya-Listrik-di-Rumah

\section{9) Korean Corner}

Pada Korean Corner, terdapat 4 prinsip universal design yang tidak memenuhi syarat, yaitu prinsip ke-1, ke2 , ke-5, dan ke-6. Hal yang tidak memenuhi prinsip universal design yang pertama dan kedua adalah tidak ada kursi pada area Korean corner yang memungkinkan pengunjung mudah lelah dan tidak nyaman ketika duduk di karpet. Solusi design yang dapat ditawarkan adalah dengan memberi beberapa bantalan duduk pada area ini sehingga pengunjung lebih nyaman ketika duduk lesehan. Pada area ini memang sengaja tidak diberi kursi atau mengadopsi dari budaya Korea tradisional.
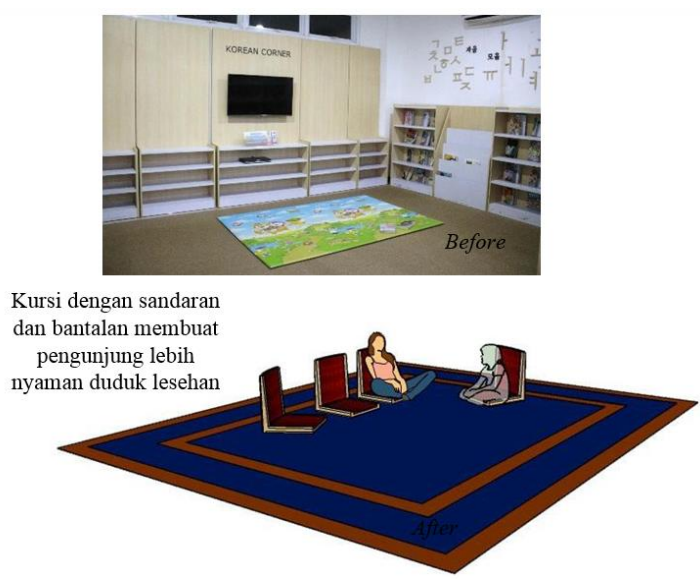

Gambar 23. Solusi desain untuk kursi pada Korean Corner. Sumber: Desain Penulis (2017)
Hal yang tidak sesuai dengan prinsip universal design ke-5 adalah resiko terjadinya kecelakaan akibat peletakan $d v d$ player yang terjangkau oleh anak-anak. Hal ini tidak dapat dipungkiri melihat sifat alamiah anakanak yang cenderung usil dan memiliki rasa ingin tahu tinggi. Solusi design yang dapat dilakukan untuk mengatasi masalah ini adalah dengan mendesain rak dvd dengan penutup kaca yang disertai dengan kunci, sehingga tidak mudah bagi anak-anak untuk mengutakatik dvd player. Warna yang digunakan adalah biru dan oranye sebagai corporate identity Perpustakaan Umum Balai Pemuda. Selain itu peletakkan rak dvd yang awalnya di bawah didesain $60 \mathrm{~cm}$ diatas lantai agar jangkauan lebih nyaman bagi pengguna, juga lebih aman dari jangkauan anak-anak.Terdapat space pada bagian bawah yang berguna bagi kaki pengunjung yang menggunakan kursi roda.

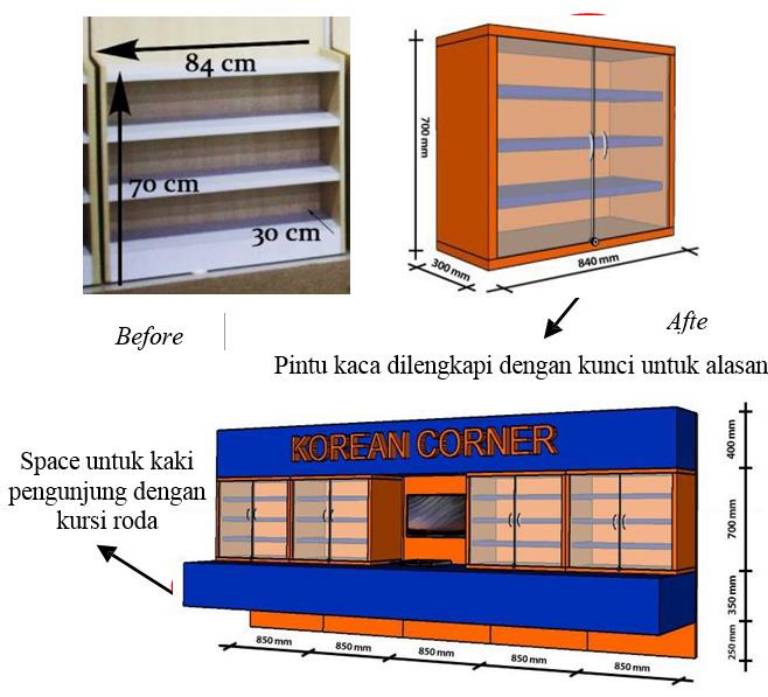

Gambar 24. Solusi desain untuk rak dvd Korean Corner. Sumber: Desain Penulis (2017)

Hal yang tidak sesuai dengan prinsip universal design ke-6 adalah ketinggian rak buku Korea yaitu $2 \mathrm{~m}$ sehingga menyulitkan pengunjung anak-anak dan pengguna kursi roda apabila hendak mengambil buku pada rak paling atas. Solusi design yang dapat diterapkan adalah dengan membagi ketinggian rak buku menjadi 2 macam. Rak buku yang pertama setinggi 170 $\mathrm{cm}$. Rak buku yang kedua setinggi $85 \mathrm{~cm}$ yang bertujuan untuk membantu pengunjung yang kesulitan menggapai buku pada rak tinggi.
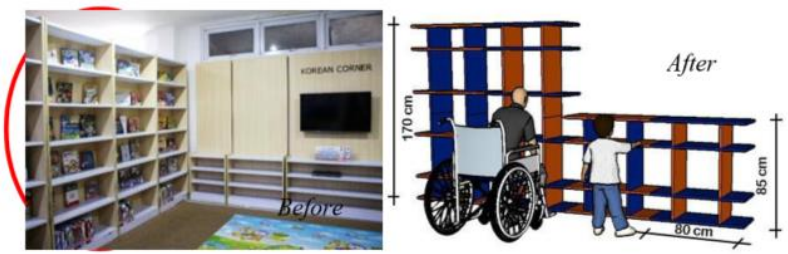

Gambar 25. Solusi desain untuk rak buku Korean Corner. Sumber: Desain Penulis (2017)

\section{0) Ruang Referensi \& Australia Corner}

Pada Ruang Referensi \& Australia Corner, terdapat 4 prinsip universal design yang tidak memenuhi syarat, yaitu prinsip ke-1, ke-2, ke-4, dan ke-6. Hal yang tidak memenuhi prinsip universal design pertama dan kedua 
adalah faktor tidak terdapat fasilitas yang memadai untuk kenyamanan pengguna saat membaca pada area ini karena hanya terdapat karpet. Solusi design yang dapat diwujudkan adalah dengan mendesain meja dan tempat duduk agar pengunjung lebih nyaman ketika membaca pada area ini. Meja yang berbentuk octagon atau segi delapan dikelilingi oleh sebuah massa yang mengikuti bentuk meja tersebut. Massa ini berfungsi sebagai tempat duduk bagi pengunjung yang ingin membaca buku pada ruang ini. Bagi pengunjung yang sudah lanjut usia, fasilitas meja dan tempat duduk sangat membantu dalam hal durasi serta kenyamanan saat membaca. Bagi pengunjung yang menggunakan kursi roda, dapat membaca buku sambil duduk di kursi rodanya.

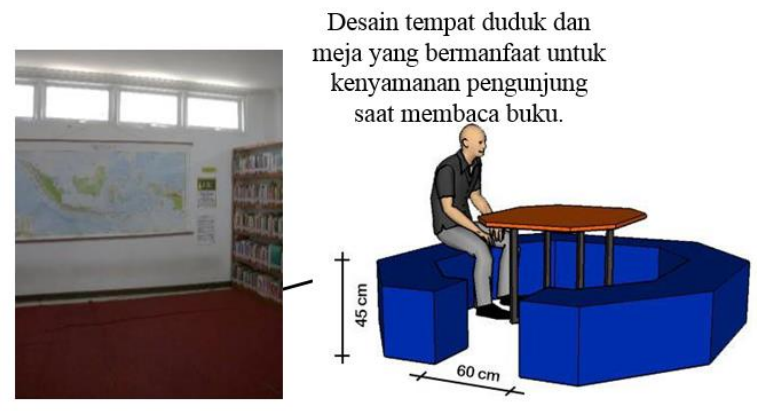

Gambar 26. Solusi desain untuk area baca ruang teferensi \& Australia corner. Sumber: Desain Penulis (2017)

Hal yang tidak memenuhi syarat prinsip universal design yang ke-4 adalah tidak adanya signage yang menunjukkan bahwa ruang ini merupakan tempat koleksi buku-buku referensi seperti kamus dan encyclopedia serta buku-buku import dari Australia. Pengunjung menjadi bingung buku apa saja yang terdapat pada ruang ini, sehingga harus melihat jarak dekat pada rak terlebih dahulu. Solusi design yang dapat diusulkan adalah memberi hanging signage diatas area ini bertuliskan "Reference \& Australia Corner". Tujuan pemilihan jenis hanging signage adalah agar dapat terlihat oleh pengunjung walaupun dari kejauhan.

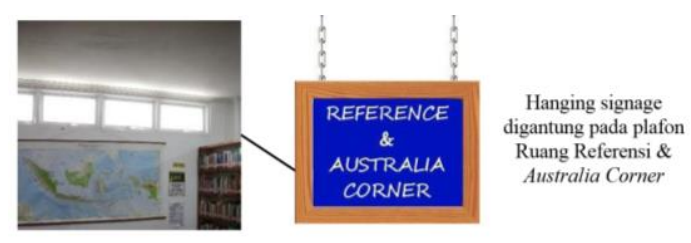

Gambar 27. Solusi desain untuk signage ruang referensi \& Australia corner. Sumber: Desain Penulis (2017)

Hal yang kurang memenuhi syarat universal design ke-6 yaitu mengenai ketinggian rak buku yang mencapai $2 \mathrm{~m}$. Bagi pengunjung yang menggunakan kursi roda dan anak-anak akan memerlukan usaha yang cukup besar apabila hendak mengambil buku pada rak yang diatas. Solusi design yang dapat ditawarkan adalah mendesain rak buku dengan perbedaan ketinggian, sehingga bukubuku yang sekiranya diminati anak-anak dapat diletakkan pada rak yang lebih rendah.

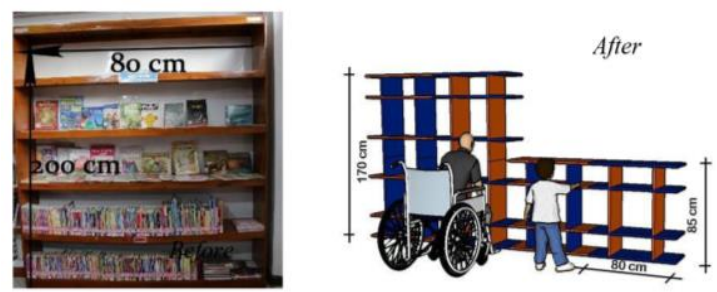

Gambar 28. Solusi desain untuk rak buku Ruang Referensi \& Australia corner. Sumber: Desain Penulis (2017)

\section{1) Kamar Kecil / Toilet}

Pada Kamar Kecil / Toilet Perpustakaan, terdapat 2 prinsip universal design yang tidak memenuhi syarat, yaitu prinsip ke- 1 dan ke-2. Terdapat 2 hal yang tidak memenuhi syarat kedua prinsip universal design tersebut hingga menjadi masalah. Masalah pertama adalah mengenai tidak adanya kamar kecil / toilet khusus untuk pengunjung disable, sehingga pengunjung dengan kursi roda yang hendak buang air akan kesulitan menggunakan toilet yang tersedia. Solusi design yang ditawarkan untuk menyelesaikan masalah ini adalah dengan mendesain satu kamar kecil / toilet khusus untuk pengunjung disable. Ukuran minimal untuk kamar kecil / toilet khusus disable adalah $1675 \mathrm{~mm} \mathrm{x} 1525 \mathrm{~mm}$ [10]. Lantai toilet menggunakan keramik dengan tekstur kasar agar tidak licin.Toilet juga dilengkapi dengan grab bars pada dinding dekat kloset dan wastafel untuk memudahkan pengunjung duduk dan berdiri. Selain itu terdapat tissue, sabun, cermin, serta tempat sampah sebagai pelengkap fasilitas.
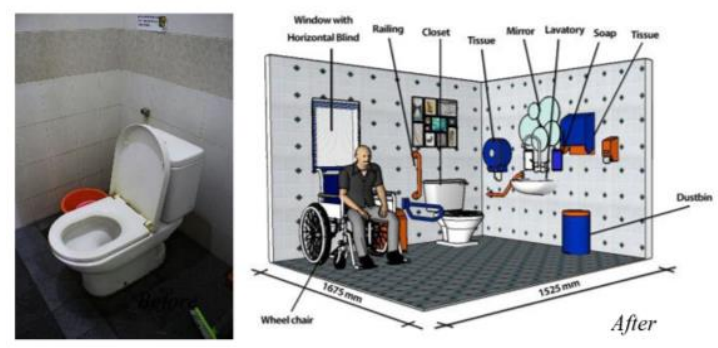

Gambar 29. Solusi desain untuk toilet disable. Sumber: Desain Penulis (2017)

Masalah kedua adalah mengenai wastafel / lavatory yang berada di depan kedua toilet. Pengunjung yang menggunakan kursi roda dikhawatirkan mengalami kesulitan pada saat menggunakan wastafel / lavatory dikarenakan pada bagian bawah wastafel tertutup sehingga tidak terdapat space untuk kaki pengguna kursi roda. Solusi design yang dapat ditawarkan adalah dengan mendesain wastafel tanpa kabinet bawah sehingga pengunjung yang menggunakan kursi roda dapat menggunakan wastafel dengan nyaman. Selain itu juga menambahkan desain wastafel sesuai dengan ergonomi anak. 


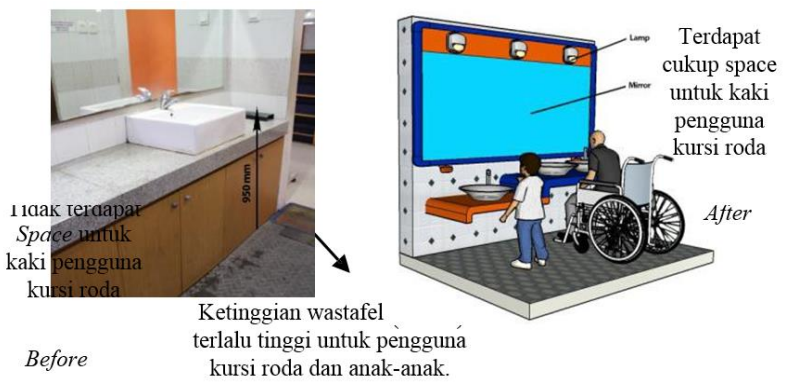

Gambar 30. Solusi desain untuk wastafel / lavatory. Sumber: Desain Penulis (2017)

\section{SIMPULAN}

Berdasarkan analisis data yang dilakukan, hasil penelitian dapat diuraikan simpulan sebagai berikut.

1. Ruangan pada Perpustakaan Umum di Balai Pemuda Kota Surabaya yang sudah sesuai dengan TPUD, adalah ruang kidsmart dan internet service area saja. Sedangkan 11 ruang lainnya, baru menerapkan beberapa prinsipnya saja yaitu: area akses masuk perpustakaan, lobby, ruang loker, front office, ruang majalah, ruang baca, ruang anak \& dyslexia corner, Bank Indonesia corner, Korean corner, Ruang referensi \& Australia corner, serta toilet.

2. Jenis solusi desain yang diusulkan disesuaikan dengan TPUD yang belum diaplikasikan pada ruangan tertentu, yaitu: (a) mengubah desain yang mudah digunakan oleh pengunjung dengan kursi roda, anakanak, dan lansia; (b) mengubah tata letak fasilitas yang tersedia, agar lebih efektif; (c) menambah keterangan pada signage untuk memperjelas informasi; (d) menambah sistem keamanan pada ramp dan stopkontak; (e) menambah desain toilet khusus difabel; serta (f) mendesain ulang area washtafel yang dapat digunakan oleh pengunjung dengan kursi roda dan anak-anak.

TPUD diharapkan mampu menjembatani isu penyediaan fasilitas untuk kepentingan umum, walaupun bukan dikategorikan sebagai fasilitas umum tetapi berdampak pada pemikiran yang lebih universal bahwa manusia harus hidup berdampingan karena setara sehingga perlu dapat perhatian yang sama. Para desainer, seharusnya sudah mengembangkan wawasan desainnya agar tidak semata-mata hanya berpikir untuk kepentingan manusia tanpa berkebutuhan khusus saja. Siapapun juga yang melibatkan dirinya dalam kegiatan desain, selayaknya perlu melakukan penelitian lanjutan mengenai isu universal design agar secara faktual dan aktual didapatkan informasi lengkap tentang unsur desain yang kurang memperhatikan TPUD tersebut. Kekurangan dari penelitian ini sendiri adalah peneliti tidak melakukan simulasi dengan menggunakan kursi roda, sehingga kurang akurat dalam menyimpulkan permasalahan yang dialami pengunjung yang menggunakan kursi roda. Bagi peneliti dengan topik universal design selanjutnya, disarankan untuk melakukan simulasi dengan berbagai pengunjung yang memiliki kebutuhan khusus sehingga analisa dan solusi desainnya pun lebih jitu.

\section{REFERENSI}

[1] "Literasi Rendah Ladang Hoax." Kompas 7 Feb. 2017: 115

[2] S., Sutarno. Manajemen Perpustakaan. Jakarta: Samitra Media Utama, 2003.

[3] Moleong, J. Metode Penelitian Kualitatif. Bandung: PT Rosdakarya, 2007.

[4] Riverdale and IDEO. Design Thinking for Educators. 4, 2011.

[5] Lockwood, Thomas. Design Thinking: Integrating Innovation, Customer Experience, and Brand Value. (pp 50) New York: Allworth Press, 2010.

[6] Ambrose, Gavin and Harris, Paul. Design Thinking. Switzerland: AVA Publishing. 12, 2010.

[7] Lawson, Bryan. How Designer Think: The Design Process Demistified. Oxford: Architectural Press is an imprint of Elsevier, (4th edition). 34, 2005.

[8] RL Mace. Universal Design in Housing, Center for Universal Design, School of Design, North Carolina State University, Raleigh 27695- 8613, USA.

[9] Panero, Julius and Zelnik, Martin. Human Dimension \& Interior Spaces. Jakarta: Erlangga, 2003.

[10]US Departments of Veterans Affairs. VA Signage Design Guide, 2012. <http://www.wbdg.org/ccb/VA/VASIGN/signage.pdf>. 